\title{
Fear of COVID-19, Internet Addiction, Learning Burnout, and Psychological Health On Teenagers in China at Post-Pandemic Era: A Serial Mediation Model
}

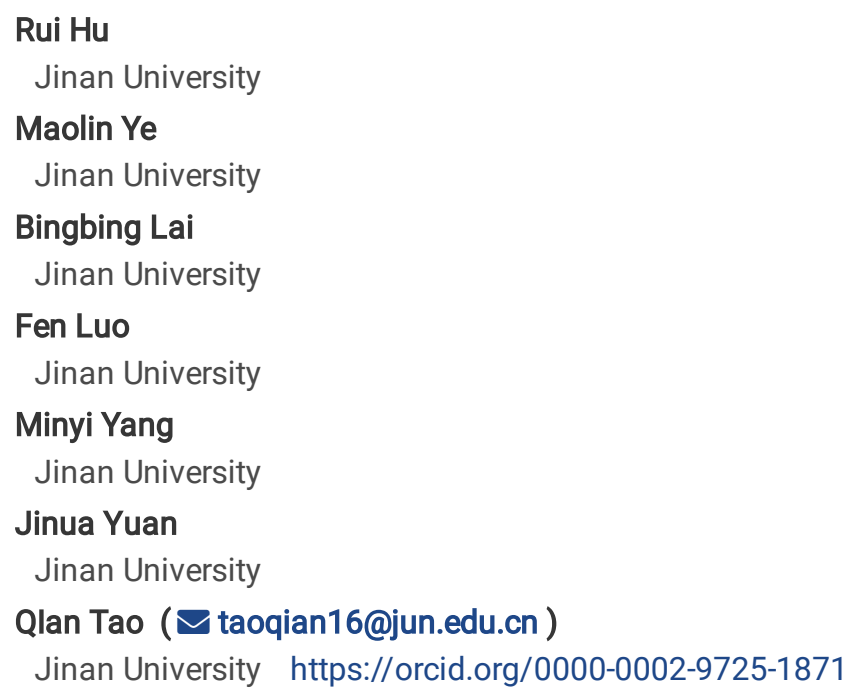

Research article

Keywords: Post-pandemic, Fear of COVID-19, Internet addiction, Learning burnout, Psychological health

Posted Date: October 11th, 2021

DOl: https://doi.org/10.21203/rs.3.rs-955207/v1

License: (ㅇ) (1) This work is licensed under a Creative Commons Attribution 4.0 International License. Read Full License 


\section{Abstract}

Background: The 2019 coronavirus disease (COVID-19) pandemic produces a long-term effect on adolescent psychological health. There were two objectives of this study: (1) To compare psychological outcomes between an early stage of pandemic and postpandemic era among junior high and high school students in China; (2) To investigate how COVID-19 fear impacts psychological health through a serial mediation of Internet addiction and learning burnout.

Methods: Two cross-sectional online surveys were conducted among Chinese adolescents at April 2020 and at April 2021, respectively. Psychological consequence was assessed by the Depression, Anxiety and Stress Scale (DASS-21). In addition, influencing factors were assessed by the Fear of COVID-19 scale (FCV-19S), Internet Addiction Test (IAT), and Maslach Burnout Inventory-Student Survey (MBISS).

Results: Our sample comprised 501 junior high school students and 540 high school students. There was a significant increase in symptoms of depression $\left(\chi^{2}=7.03, P<0.01\right)$, anxiety $\left(\chi^{2}=35.50, P<0.01\right)$, and stress $\left(\chi^{2}=13.60, P<0.01\right)$ at post-pandemic era compared with an early stage of COVID-19. Importantly, Internet addiction and learning burnout were identified the serial mediators between fear of COVID-19 and psychological health $(\beta=0.02,95 \% \mathrm{Cl}=0.01,0.03)$.

Conclusions: During the post-pandemic era in China, an increased number of junior high and high school students' psychological health was affected compared with the number during the pandemic. Furthermore, fear of COVID-19 influenced psychological health through first Internet addiction and then learning burnout.

\section{Introduction}

Public health emergencies remain one of the biggest threats to the well-being of human race. The coronavirus disease-19 (COVID-19) pandemic has been lasted for a long time and significant changes to our daily lives have occurred, such as social distancing, working from home, temporary unemployment, financial strain, and home-schooling of children. Serious effect of the COVID-19 pandemic on mental health and emotional well-being has been highlighted (1). The common psychological symptoms due to the pandemic included depression, anxiety, insomnia, fear, stress, irritability, and even post-traumatic stress disorder (2).

Children are particularly vulnerable during the pandemic because they have limited coping strategies and limited understanding of the pandemic. Serious concerns about the mental health of children and adolescents during the pandemic have been raised (3). At an earlier stage of pandemic, most educational institutions have temporarily suspended their traditional in-person classroom courses and have to adopt online education where teaching is provided remotely on digital platforms. As a consequence, school students faced with a variety of challenges, such as prolonged home stay, difficulties in schoolwork, increased loneliness, increased academic pressure, increased conflict with parents, reduced physical activity, and reduced social interaction with peers, which can create dramatic psychological effects and increase risk for mental health problems (4). For instance, our previous study found that more than one fifth of junior and high school students in China reported symptoms of depression, anxiety, and stress at the initial stage of COVID-19 (5). Although China seems to have kept COVID-19 largely under control, we believe that the psychological consequence on the children and teenagers are long-term. We have only identified one study to compare mental health status of adolescents between different stages of COVID-19 outbreak (February 2020 versus April 2020), and the results found the prevalence of depression and anxiety increased from $36.6 \%$ and $19-57 \%$ and $36.7 \%$, respectively (6). However, comparisons of psychological health on children and teenagers have not been made between an early and a late stage of COVID-19 pandemic. The first objective of present study aims to investigate the effect of COVID-19 pandemic on mental health of children and teenagers in the post-COVID era and compare the results with our previous study.

The spread of online learning may lead to an increased risk of developing pathological use of the internet or internet addiction. Internet addiction is considered an impulse-control disorder characterized by an extensive use of the internet that cause neurological impairments, psychological distress, and significant functional impairments in daily life (7). Functional impairments caused by internet addiction included sleep disturbances, impaired academic performance, interpersonal problems, and time management problems (8). Furthermore, there was an association between internet addiction and negative emotions such as depression and anxiety (9). On one hand, internet addiction predicted impaired mental health (10). On the other hand, individuals who have emotional problems tend to spend more time online, mainly because of the anonymous nature of the internet. In the last two decades, we have to admit that the number of adolescent internet users had been increasing dramatically in the world and internet addiction has become a worldwide health issue (11). For instance, a cross-sectional survey on 14,296 high school students in China showed that $12.2 \%$ of the 12,446 internet users were addicts (12). Another nationally representative sample study in China showed that the prevalence of internet 
addiction in the total sample was $6.3 \%$ and among internet users was $11.7 \%$ (13). A recent meta-analysis included 48,090 students in the analysis and identified 6548 (13.62\%) as excessive internet users (14). A number of epidemiology studies suggested that a younger age and male were associated with a higher risk of internet addiction (15). Since the outbreak of COVID-19, children and adolescents spent most of their time interacting with internet. As a maladaptive coping strategy, internet addiction is becoming more prevalent among adolescents in China as well as other countries during the COVID-19 pandemic (16).

Burnout occurs when coping is limited in stressful situations. The COVID-19 pandemic may also lead to a passive mental state of students to the learning, that is, learning burnout. Students with learning burnout often demonstrate decreased enthusiasm for learning and negative attitudes toward learning. Learning burnout in students were associated with a variety of negative outcomes, such as poor academic performance (17), mental disorders, increased loneliness (18), increased tendency to drop out from school (19), and even suicide (20). Two longitudinal studies in adolescents revealed reciprocal cross-lagged paths between excessive internet use and school burnout (21). More recently, a study revealed that COVID-19 anxiety significantly and uniquely linked to learning related cynicism, which was a cognitive aspect of learning burnout.

There are a lot of commonalities between learning burnout and internet addiction, such as both are prevalent among children and adolescents, both are related to chronic stress, both are associated with social withdrawal, isolation, and loneliness, and both have negative effect on emotional wellbeing. However, few studies investigated the relation between learning burnout and internet addiction in adolescents. As fear may be a central construct in explaining the negative consequence due to the COVID-19 pandemic, the present study is dedicated to understand the underlying mechanisms between COVID-19 fear and psychological health in Chinese adolescents during the post-COVID era with two gendered models. In particular, we assume that the two mediators of internet addiction and learning burnout may co-play a serial mediating role in the relationship of COVID-19 fear and psychological health. We hereby proposed the following three hypotheses for this study:

H1: Internet addiction plays a mediating role between COVID-19 fear and psychological health;

H2: Learning burnout also plays a mediating role between COVID-19 fear and psychological health;

H3: Internet addiction and learning burnout co-play a serial mediating role in the relationship of COVID-19 fear and psychological health.

\section{Methods}

\section{Procedure and participants}

A cross-sectional online survey using structural questionnaires was conducted on the Questionnaire Star platform from March to May, 2021. Participants were recruited from Guangzhou No. 75 Middle School and Longchuan No. One Middle school in Guangdong, China. The study was approved by the Ethics Committee of Jinan University, and all participants provided consent before they answered the questionnaires.

\section{Measures}

\section{Fear of COVID-19 scale (FCV-19S)}

The FCV-19S was developed by Ahorsu and colleagues in assessing fear of COVID-19 in general population (22). According to the authors, the scale was constructed based on an extensive review of fear, expert evaluations, and participant interviews. The scale contains seven items and each item is rated on a 5-point Likert scale ranging from 1 (strongly disagree) to 5 (strongly agree). The total score ranges from 7 to 35 , with a higher score indicating more fear about COVID-19. The psychometric properties of the Chinese version were examined by Chi and colleagues in 1700 Chinese participants, and the results indicated that the Chinese version of FCV-19S had good internal consistency reliability $(a=0.92)$, composite reliability $(C R=0.92)$, and good validity in Chinese communities (23). In our current sample, the value of Cronbach's alpha for FCV-19S was 0.92 .

\section{Internet Addiction Test (IAT)}

The IAT was developed by Young to measure the presence and severity of the Internet dependency in a North American population sample (24). The scale contains 20 items and each item is rated on a 5-point scale ranging from 0 (does not apply) to 5 (always). The total score ranges between 0 and 100, with a higher score representing a higher level of severity of the Internet compulsivity and 
addiction (25). The Chinese version of the IAT was examined by Chang in 410 Hong Kong university undergraduates and it demonstrated good criterion validity (26). Cronbach's a coefficient was 0.79 in the current sample.

\section{Maslach Burnout Inventory-Student Survey (MBI-SS)}

The MBI-SS was developed by Maslach and Jackson to measure the burnout syndrome in student populations (27). The MBI-SS includes three subscales to evaluate different domains of learning burnout: emotional exhaustion, cynicism, and academic efficacy. The scale consists of 15 items and each item is rated on a 7-point Likert scale ranging from 0 (never) to 6 (every day). The total score ranges from 0 to 90, with a higher score indicating more serious learning burnout. The factorial validity of the Chinese version of the MBI-SS was examined by Hu and Schaufei in Chinese high school students and it demonstrated threeOdimensional structure was invariant across three samples (28). Cronbach's a coefficient was 0.94 in the current sample.

\section{1-item Depression Anxiety Stress Scales (DASS-21)}

The DASS-21 is a self-report questionnaire evaluating symptoms of depression, anxiety, and stress. Each subscale comprises 7 items and each item is rated on a 4-point scale, ranging from 0 (did not apply to me at all) to 3 (applied to me very much). The total score of each subscale was ranged from 0 to 42 . A higher total score indicates a more severe level of depression, anxiety, or stress. The DASS-21 has been demonstrated to be a reliable and valid measure in assessing mental health in the Chinese population (29). Furthermore, the DASS has been widely used in children and adolescents between the ages of 7 and 15 years (30). In our current sample, the value of Cronbach's alpha for the full scale and three subscales were 0.95 (full scale), 0.88 (depression), 0.85 (anxiety), and 0.87 (stress), suggesting good reliability of the Chinese version of the DASS-21.

\section{Statistical analyses}

The analyses were performed using SPSS version 25 (IBM, Chicago, IL, USA). First, descriptive analyses were conducted to describe the demographic characteristics of Chinese junior high and senior high school students. Second, a set of ANOVAs were conducted to examine the effect of gender and grade on COVID-19 fear, Internet addiction, learning burnout and psychological health of students. Third, Pearson correlation analyses were performed to examine the associations among the study variables. Finally, mediation analysis based on a series of regression was conducted to examine the hypothesized mediation models (31). Demographic characteristics, such as age, gender, education levels of parents, and annual income were included in the model as covariates. The models were tested using the bootstrap method, based on 10,000 bias-corrected $95 \%$ confidence intervals (Cls). The mediation effect was considered significant when the Cls did not contain zero. The total effect was the sum of direct effect and indirect effect. The analyses were performed using SPSS (version 19.0).

\section{Results}

\section{Characteristics of participants}

The demographic details were shown in Table1. The online survey was completed by 1041 participants, with $42.75 \%$ male (mean age = 15.60 years) and $57.25 \%$ female (mean age $=15.56$ years). Among them, $48.13 \%$ were junior high school students and $51.87 \%$ were senior high school students. Most of the participants' parents ( $71.18 \%$ for father and $70.99 \%$ for mother) had a high school degree. The majority (84.63\%) had an annual household income below CNY 200,000. Findings from ANOVAs revealed a significant main effect of gender in FCV-19S $(F=9.97, P<0.01)$, MBI-SS $(F=23.65, P<0.01)$, and DASS-21 $(F=11.98, P<0.01)$. There was no significant gender effect in IAT $(F=0.44, P=0.51)$. Compared to boys, girls reported higher levels of fear of COVID-19, higher levels of learning burnout, and more severe mental health symptoms. With regards to grade, findings from ANOVAs revealed a significant main effect in IAT $(F=58.61$, $P<0.01)$, MBI-SS $(F=10.85, P<0.01)$, and DASS-21 $(F=7.46, P<0.01)$. But there was no significant grade effect in FCV-19S $(F=0.47$, $P=0.49)$. Compared with junior school students, high school students demonstrated higher levels of Internet addiction, higher levels of learning burnout, and more severe mental health symptoms. Means and standard deviations of the variables by gender and grade were presented in Table 2.

Table1. Characteristics of the participants 


\begin{tabular}{|ll|}
\hline & $\mathrm{N}(\%) / \mathrm{M} \pm \mathrm{SD}$ \\
\hline Gender & \\
\hline Male & $445(42.75)$ \\
\hline Female & $596(57.25)$ \\
\hline Age $(\mathrm{M} \pm \mathrm{SD})$ & $15.58 \pm 1.92$ \\
\hline Grade & \\
\hline Junior school & $501(48.13)$ \\
\hline High school & $540(51.87)$ \\
\hline Father's education level & \\
\hline Primary school & $94(9.03)$ \\
\hline High school & $741(71.18)$ \\
\hline College & $174(16.71)$ \\
\hline Graduate & $32(3.07)$ \\
\hline Mother's education level & \\
\hline Primary school & $132(12.68)$ \\
\hline High school & $739(70.99)$ \\
\hline College & $155(14.89)$ \\
\hline Graduate & $15(1.44)$ \\
\hline Annual household income & \\
\hline 区50,000 & $371(35.64)$ \\
\hline $50,000-200,000$ & $510(48.99)$ \\
\hline $200,000-50,000$ & $139(13.35)$ \\
\hline \&500,000 & $21(2.02)$ \\
\hline
\end{tabular}

Table2. Study variables by grade and gender

\begin{tabular}{|c|c|c|c|c|c|c|c|c|}
\hline & Grade & & & & Gend & & & \\
\hline & $\begin{array}{l}\text { Junior } \\
\text { \501区 }\end{array}$ & $\begin{array}{l}\text { High } \\
(540)\end{array}$ & $F$ & $P$ & $\begin{array}{l}\text { Boys } \\
(445)\end{array}$ & $\begin{array}{l}\text { Girls } \\
(596)\end{array}$ & $F$ & $P$ \\
\hline $\begin{array}{l}\text { COVID- } \\
19 \text { fear }\end{array}$ & $10.53 \pm 5.33$ & $10.76 \pm 5.10$ & 0.47 & 0.49 & $10.06 \pm 4.88$ & $11.09 \pm 5.40$ & 9.97 & $\otimes 0.01$ \\
\hline Internet addiction & $39.47 \pm 15.63$ & $46.76 \pm 15.06$ & 58.61 & $\mathbb{\nabla 0 . 0 1}$ & $42.87 \pm 15.93$ & $43.53 \pm 15.63$ & 0.44 & 0.51 \\
\hline $\begin{array}{l}\text { Learning } \\
\text { burnout }\end{array}$ & $36.91 \pm 14.99$ & $39.91 \pm 14.44$ & 10.85 & 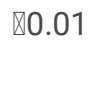 & $35.92 \pm 15.23$ & $40.37 \pm 14.14$ & 23.65 & $\varangle 0.01$ \\
\hline Psychological health & $20.79 \pm 23.59$ & $24.68 \pm 22.38$ & 7.46 & 0.01 & $19.96 \pm 21.59$ & $24.93 \pm 23.87$ & 11.98 & $\otimes 0.01$ \\
\hline
\end{tabular}

\section{Psychological health in the first and second survey}

Prevalence of depression, anxiety, and stress symptoms were compared between the 1 st and 2 nd surveys (Table 3 ). The 2 nd survey had a higher prevalence of anxiety $\left(\chi^{2}=35.50, P<0.01\right)$, depression $\left(\chi^{2}=7.03, P<0.01\right)$ and stress symptoms $\left(\chi^{2}=13.60, P<0.01\right)$ than the 1 st survey. 
Table 3. Psychological outcomes at the $1^{\text {st }}$ and $2^{\text {nd }}$ survey

\begin{tabular}{|c|c|c|c|c|c|c|c|c|c|}
\hline & \multicolumn{3}{|c|}{ DASS-Anxiety } & \multicolumn{3}{|c|}{ DASS-Depression } & \multicolumn{3}{|c|}{ DASS-Stress } \\
\hline & $1^{\text {st }}$ survey & $2^{\text {nd }}$ survey & $c^{2}$ & $1^{\text {st }}$ survey & $2^{\text {nd }}$ survey & $c^{2}$ & $1^{\text {st }}$ survey & $2^{\text {nd }}$ survey & $c^{2}$ \\
\hline & $\mathrm{n}(\%)$ & $\mathrm{n}(\%)$ & & n (\%) & n (\%) & & n (\%) & $\mathrm{n}(\%)$ & \\
\hline Whole & $275(26.9)$ & 408(39.2) & $35.50 * \star$ & $225(22.0)$ & $281(27.0)$ & $7.03^{* *}$ & $270(26.4)$ & $352(33.8)$ & 13.60 ** \\
\hline \multicolumn{10}{|l|}{ Gender } \\
\hline Male & $128(24.3)$ & $150(33.7)$ & $10.48^{\star \star}$ & $110(20.9)$ & $101(22.7)$ & 0.47 & $134(25.4)$ & 139(31.2) & $4.03^{\star}$ \\
\hline Female & $147(29.6)$ & $258(43.3)$ & $21.84^{\star \star}$ & $115(23.1)$ & $180(30.2)$ & $6.86 * *$ & $136(27.4)$ & 213(35.7) & $8.74^{\star \star}$ \\
\hline \multicolumn{10}{|l|}{ Grade } \\
\hline Junior & $124(25.2)$ & $175(34.9)$ & $11.16^{\star \star}$ & 102(20.7) & $120(24.0)$ & 1.48 & $112(22.8)$ & $141(28.1)$ & 3.78 \\
\hline High & $151(28.4)$ & $233(43.1)$ & $25.41^{\star \star}$ & $123(23.1)$ & $161(29.8)$ & $6.17^{*}$ & $158(29.7)$ & 211(39.1) & $10.43^{\star *}$ \\
\hline \multicolumn{10}{|l|}{$\begin{array}{l}\text { Father's } \\
\text { education } \\
\text { level }\end{array}$} \\
\hline $\begin{array}{l}\text { sHigh } \\
\text { school }\end{array}$ & $223(27.4)$ & $344(41.2)$ & $34.60 * \star$ & $179(22.0)$ & $237(28.4)$ & $8.85^{\star \star}$ & $222(27.3)$ & $300(35.9)$ & $14.15^{\star \star *}$ \\
\hline$\underset{\text { Colleage }}{\geq}$ & $52(24.6)$ & 64(31.1) & 2.14 & $46(21.8)$ & $44(21.4)$ & 0.01 & $48(22.7)$ & $52(25.2)$ & 0.36 \\
\hline \multicolumn{10}{|l|}{$\begin{array}{l}\text { Mother's } \\
\text { education } \\
\text { level }\end{array}$} \\
\hline $\begin{array}{l}\text { <High } \\
\text { school }\end{array}$ & $238(27.8)$ & $357(41.0)$ & $33.42^{\star \star}$ & 188(21.9) & $244(28.0)$ & $8.51^{\star \star}$ & $232(27.1)$ & $309(35.5)$ & $14.19 \star \star$ \\
\hline$\underset{\text { Colleage }}{\geq}$ & $37(22.2)$ & $51(30.0)$ & 2.69 & $37(22.2)$ & $37(21.8)$ & 0.01 & $38(22.8)$ & $43(25.3)$ & 0.30 \\
\hline \multicolumn{10}{|l|}{$\begin{array}{l}\text { Annual } \\
\text { household } \\
\text { income }\end{array}$} \\
\hline$\leq 200,000$ & $236(27.2)$ & $358(40.6)$ & $35.25^{\star \star}$ & $195(22.5)$ & $247(28.0)$ & $7.19 * *$ & 233(26.8) & $301(34.2)$ & $11.05^{\star \star *}$ \\
\hline$\otimes 200,000$ & $39(25.0)$ & $50(31.3)$ & 1.53 & $30(19.2)$ & $34(21.3)$ & 0.2 & $37(23.7)$ & $51(31.9)$ & 2.62 \\
\hline
\end{tabular}

\section{* $P<0.05$ ** $P<0.01$}

\section{Correlation analyses}

COVID-19 fear was significantly associated with Internet addiction, learning burnout and psychological health, with the coefficient was $0.16,0.21$ and 0.26 , respectively. Similarly, Internet addiction was significantly associated with learning burnout and psychological health, with the coefficient was 0.40 and 0.48 , respectively. Learning burnout was significantly associated with psychological health, with the coefficient was 0.48 .

\section{The mediation analyses}

The previous analyses revealed that COVID-19 fear, Internet addiction, learning burnout were correlated with psychological health, therefore all these correlated variables were included in the mediation analyses. Results of hypothesis testing were summarized in Table 4 and Figure 1. The $\mathrm{H} 1$ indicates that Internet addiction plays a mediating role between COVID-19 fear and psychological health. The regression results indicated that fear of COVID-19 positively predicted both Internet addiction $(\beta=0.16, P<0.01)$ and psychological health $(\beta=0.14, P<0.01)$, Internet addiction also positively predicted psychological health $(\beta=0.32, P<0.01)$. The indirect effect of COVID-19 fear $\rightarrow$ Internet addiction $\rightarrow$ psychological health was significant $(\beta=0.05,95 \% \mathrm{Cl}=0.03$ to 0.08$)$. The $\mathrm{H} 2$ indicates that learning burnout also plays a mediating role between COVID-19 fear and psychological health. The regression results indicated that fear of COVID-19 positively predicted both learning burnout $(\beta=0.15, P<0.01)$ and psychological health $(\beta=0.14, P<0.01)$, learning burnout 
also positively predicted psychological health $(\beta=0.32, P<0.01)$. The indirect effect of COVID-19 fear $\rightarrow$ learning burnout $\rightarrow$ psychological health was significant $(\beta=0.05,95 \% \mathrm{Cl}=0.03,0.07)$. The $\mathrm{H} 3$ indicates that Internet addiction and learning burnout co-play a serial mediating role in the relationship of COVID-19 fear and psychological health. The indirect effect of COVID-19 fear $\rightarrow$ Internet addiction $\rightarrow$ learning burnout $\rightarrow$ psychological health was significant $(\beta=0.02,95 \% \mathrm{Cl}=0.01,0.03)$. No significant results were found in other paths and other indirect effects.

Table 4

Direct and indirect effects of COVID-19 fear on psychological health

\begin{tabular}{|lll|}
\hline Path & Effect & $95 \%$ Cl \\
\hline COVID-19 fear $\rightarrow$ Psychological health & 0.14 & {$[0.09,0.19]$} \\
\hline COVID-19 fear $\rightarrow$ Internet addiction $\rightarrow$ Psychological health & 0.05 & {$[0.03,0.08]$} \\
\hline COVID-19 fear $\rightarrow$ Learning burnout $\rightarrow$ Psychological health & 0.05 & {$[0.03,0.07]$} \\
\hline COVID-19 fear $\rightarrow$ Internet addiction $\rightarrow$ Learning burnout $\rightarrow$ Psychological health & 0.02 & {$[0.01,0.03]$} \\
\hline
\end{tabular}

\section{Discussion}

The present study has two objectives. (1) To the best of our knowledge, this was the first study to compare psychological consequence among children and teenagers at an early and a late stage of COVID-19 pandemic. Compared with the initial of COVID-19 outbreak, the prevalence of anxiety and stress symptoms significantly increased at the post-pandemic era. (2) We aim to investigate the mediating role of Internet addiction and learning burning on relation between COVID-19 fear and psychological health. Compared with boys, girls reported higher levels of COVID-19 fear. Furthermore, COVID-19 caused a more serious impact on the psychological health of high school students and girls. Importantly, Internet addiction and learning burnout played a serial mediating role on the relationship between COVID19 fear and psychological health.

The main findings suggested that fear of COVID-19 influenced psychological health through first Internet addiction and then learning burnout. Although there were significant gender differences in COVID-19 fear, learning burnout, and psychological health, the serial mediation model was established in whole sample, female sample, and male sample. The association between COVID fear and Internet addiction was supported by the interaction of Person-Affect-Cognition-Execution (I-Pace) model for addictive behaviors, which explained symptoms of Internet addiction as responses to environmental stressors driving excessive addictive behaviors to mitigate negative emotions $(32,33)$. Without effective coping strategies, children and teenagers may intensify the use of Internet to handle the fear of COVID-19 at post-pandemic era. The association between Internet addiction and psychological health has been confirmed in many studies (34). However, this is not telling the whole truth, as Internet addiction will have to work on psychological health through a second mediator - learning burnout. When students are required to keep social distance in real word due to fear of COVID-19, they spend more time online, and finally their academic engagement and performance will be negatively affected. As a result, learning burnout occurs, which in turn will negatively affect psychological health in children and teenagers.

The present study demonstrated higher levels of fear of COVID-19 in girls than boys. This finding was consistent with a previous study demonstrated higher levels of fear of COVID-19 in female than male in a sample of 772 Cuban participants (35). Accumulated evidence has shown greater psychological vulnerability in female compared to male during the COVID-19 pandemic (36). For instance, a recent study on 1210 respondents showed that female gender was associated with higher levels of stress, anxiety, and depression during the initial stage of COVID-19 (37). Interestingly, at the post-COVID era, the current results suggested a higher prevalence of anxiety and stress symptoms in girls than boys, but no gender difference was found for depressive symptoms. As the pandemic continued, chronic stress can lead adverse effects on central nervous system and can result in anxiety (38). Indeed, female had a higher lifetime risk of posttraumatic stress disorder than male (36), this might due to the fact that female had more sensitive stress hormone systems (39). In addition, we found that girls had higher levels of learning burnout than boys. This may due to the fact that girls experience more academic pressure than boys and therefore girls are more concerned about academic failure. With regards to effect of grade, the current results showed that high school students had higher levels of Internet addiction, learning burnout, and psychological symptoms than junior school students. Compared with junior school students, high school students face higher academic pressure since they need to prepare for college entrance examinations that have significant meaning for future career (40). At the time of the COVID-19 outbreak, students were taking online classes, which made it difficult to guarantee the efficiency and quality of learning. Although students 
returned to school at the post-pandemic time, their grades were declined and academic performance was impaired, which would increase their level of learning burnout.

Nevertheless, several limitations should be noted. First, considering its cross-sectional design, inferences about causal relationships in the mediation model cannot be drawn. Future studies using longitudinal data could be conducted to further confirm the direction of causality in the paths proposed in the present study. Second, since we used convenience sampling method, generalization of our findings should be cautious. Third, standardized diagnostic instruments could not be administered and only self-reported measures were used in the present study, which could only partially reflect psychological health.

\section{Conclusions}

At the post-COVID era, senior high school students were more serious than junior high school students at Internet addiction, school burnout and psychological health and girls were more serious than boys at fear of COVID-19, school burnout and psychological health. Importantly, Internet addiction and school burnout played a serial mediating role between fear of COVID-19 and psychological health.

\section{Declarations}

\section{Acknowledgement}

The authors thank the local school in Guangdong Province and students for participating in this study.

\section{Authors' contributions}

H.R., Y. M. and T.Q. coordinated the project. T.Q. designed the study. H.R., Y.M., L.B., L.F., Y.M., and Y.J. collected data. H.R. and Y.M. analyzed the data. H.R. and Y.M. wrote the first draft. T.Q. revised the manuscript. All authors provided critical feedback. All authors have read and approved the final manuscript.

\section{Funding}

This study was supported by research grants from the Science and Technology Program of Guangdong (2018B030334001).

\section{Availability of data and materials}

The data is available via the link: https://datadryad.org/stash/share/p0S25ag4L-xRWBUKIhbQdi_46-7B2B8ko2GQFqJg_-M

\section{Ethics approval and consent to participate}

This study was carried out in accordance with the recommendations of the Declaration of Helsinki with written informed consent obtained from all subjects. The protocol was approved by the Ethics Committee at Jinan University, China. All participates provided consent before they answered the questionnaires.

\section{Competing interests}

The authors have no conflicts of interest to declare.

\section{References}

1. Pfefferbaum B, North CS. Mental health and the Covid-19 pandemic. N Engl J Med. 2020;383(6):510-2.

2. Dubey S, Biswas P, Ghosh R, Chatterjee S, Dubey MJ, Chatterjee S, et al. Psychosocial impact of COVID-19. Diabetes Metabolic Syndrome: Clinical Research Reviews. 2020;14(5):779-88.

3. Zhou S-J, Zhang L-G, Wang L-L, Guo Z-C, Wang J-Q, Chen J-C, et al. Prevalence and socio-demographic correlates of psychological health problems in Chinese adolescents during the outbreak of COVID-19. Eur Child Adolesc Psychiatry. 2020;29(6):749-58.

4. Brooks SK, Webster RK, Smith LE, Woodland L, Wessely S, Greenberg N, et al. The psychological impact of quarantine and how to reduce it: rapid review of the evidence. The lancet. 2020;395(10227):912-20.

5. Zhang C, Ye M, Fu Y, Yang M, Luo F, Yuan J, et al. The psychological impact of the COVID-19 pandemic on teenagers in China. J Adolesc Health. 2020;67(6):747-55. 
6. Chen X, Qi H, Liu R, Feng Y, Li W, Xiang M, et al. Depression, anxiety and associated factors among Chinese adolescents during the COVID-19 outbreak: a comparison of two cross-sectional studies. Translational psychiatry. 2021;11(1):1-8.

7. Beard KW, Wolf EM. Modification in the proposed diagnostic criteria for Internet addiction. Cyberpsychology behavior. 2001;4(3):377-83.

8. Young K. The evolution of Internet addiction disorder. Internet addiction: Neuroscientific approaches and therapeutical interventions. New York: Springer Science + Business Media; 2015. pp. 3-17.

9. Carli V, Durkee T, Wasserman D, Hadlaczky G, Despalins R, Kramarz E, et al. The association between pathological internet use and comorbid psychopathology: a systematic review. Psychopathology. 2013;46(1):1-13.

10. Ciarrochi J, Parker P, Sahdra B, Marshall S, Jackson C, Gloster AT, et al. The development of compulsive internet use and mental health: A four-year study of adolescence. Dev Psychol. 2016;52(2):272.

11. Li L, Xu D-D, Chai J-X, Wang D, Li L, Zhang L, et al. Prevalence of Internet addiction disorder in Chinese university students: A comprehensive meta-analysis of observational studies. Journal of behavioral addictions. 2018;7(3):610-23.

12. Wang H, Zhou X, Lu C, Wu J, Deng X, Hong L. Problematic Internet use in high school students in Guangdong Province, China. PloS one. 2011;6(5):e19660.

13. Li Y, Zhang X, Lu F, Zhang Q, Wang Y. Internet addiction among elementary and middle school students in China: A nationally representative sample study. Cyberpsychology Behavior Social Networking. 2014;17(2):111-6.

14. Fumero A, Marrero RJ, Voltes D, Penate W. Personal and social factors involved in internet addiction among adolescents: A metaanalysis. Comput Hum Behav. 2018;86:387-400.

15. Weiser EB. Gender differences in Internet use patterns and Internet application preferences: A two-sample comparison. Cyberpsychology behavior. 2000;3(2):167-78.

16. Fernandes B, Biswas UN, Mansukhani RT, Casarín AV, Essau CA. The impact of COVID-19 lockdown on internet use and escapism in adolescents. Revista de psicología clínica con niños y adolescentes. 2020;7(3):59-65.

17. Fiorilli C, De Stasio S, Di Chiacchio C, Pepe A, Salmela-Aro K. School burnout, depressive symptoms and engagement: Their combined effect on student achievement. International Journal of Educational Research. 2017;84:1-12.

18. Lin S-H, Huang Y-C. Investigating the relationships between loneliness and learning burnout. Act Learn High Educ. 2012;13(3):23143.

19. Korhonen J, Linnanmäki K, Aunio P. Learning difficulties, academic well-being and educational dropout: A person-centred approach. Learning individual differences. 2014;31:1-10.

20. Dyrbye LN, Thomas MR, Massie FS, Power DV, Eacker A, Harper W, et al. Burnout and suicidal ideation among US medical students. Ann Intern Med. 2008;149(5):334-41.

21. Salmela-Aro K, Upadyaya K, Hakkarainen K, Lonka K, Alho K. The dark side of internet use: Two longitudinal studies of excessive internet use, depressive symptoms, school burnout and engagement among Finnish early and late adolescents. J Youth Adolesc. 2017;46(2):343-57.

22. Ahorsu DK, Lin C-Y, Imani V, Saffari M, Griffiths MD, Pakpour AH. The fear of COVID-19 scale: development and initial validation. International journal of mental health and addiction. 2020:1-9.

23. Chi X, Chen S, Chen Y, Chen D, Yu Q, Guo T, et al. Psychometric Evaluation of the Fear of COVID-19 Scale Among Chinese Population. Int J Ment Health Addict. 2021:1-16.

24. Young KS. Caught in the net: How to recognize the signs of internet addiction-and a winning strategy for recovery. John Wiley \& Sons; 1998.

25. Young KS, De Abreu CN. Internet addiction: A handbook and guide to evaluation and treatment. John Wiley \& Sons; 2010.

26. Chang MK, Law SPM. Factor structure for Young's Internet Addiction Test: A confirmatory study. Computers in human behavior. 2008;24(6):2597-619.

27. Maslach C, Jackson SE. The measurement of experienced burnout. Journal of organizational behavior. 1981;2(2):99-113.

28. Hu Q, Schaufeli WB. The factorial validity of the Maslach burnout inventory-student survey in China. Psychological reports. 2009;105(2):394-408.

29. Ho CS, Tan EL, Ho R, Chiu MY. Relationship of anxiety and depression with respiratory symptoms: Comparison between depressed and non-depressed smokers in Singapore. Int J Environ Res Public Health. 2019;16(1):163.

Page 9/10 
30. Szabó M. The short version of the Depression Anxiety Stress Scales (DASS-21): Factor structure in a young adolescent sample. Journal of adolescence. 2010;33(1):1-8.

31. Hayes AF. Introduction to mediation, moderation, and conditional process analysis: A regression-based approach. Guilford publications; 2017.

32. Brand M, Wegmann E, Stark R, Müller A, Wölfling K, Robbins TW, et al. The Interaction of Person-Affect-Cognition-Execution (I-PACE) model for addictive behaviors: Update, generalization to addictive behaviors beyond internet-use disorders, and specification of the process character of addictive behaviors. Neuroscience Biobehavioral Reviews. 2019;104:1-10.

33. Brand M, Young KS, Laier C, Wölfling K, Potenza MN. Integrating psychological and neurobiological considerations regarding the development and maintenance of specific Internet-use disorders: An Interaction of Person-Affect-Cognition-Execution (I-PACE) model. Neuroscience Biobehavioral Reviews. 2016;71:252-66.

34. Young KS, Rogers RC. The relationship between depression and Internet addiction. Cyberpsychology behavior. 1998;1(1):25-8.

35. Broche-Pérez Y, Fernández-Fleites Z, Jiménez-Puig E, Fernández-Castillo E, Rodríguez-Martin BC. Gender and fear of CoVID-19 in a Cuban population sample. International Journal of Mental Health and Addiction. 2020:1-9.

36. Liu N, Zhang F, Wei C, Jia Y, Shang Z, Sun L, et al. Prevalence and predictors of PTSS during COVID-19 outbreak in China hardest-hit areas: Gender differences matter. Psychiatry research. 2020;287:112921.

37. Wang C, Pan R, Wan X, Tan Y, Xu L, Ho CS, et al. Immediate psychological responses and associated factors during the initial stage of the 2019 coronavirus disease (COVID-19) epidemic among the general population in China. Int J Environ Res Public Health. 2020;17(5):1729.

38. Yaribeygi H, Panahi Y, Sahraei H, Johnston TP, Sahebkar A. The impact of stress on body function: A review. EXCLI J. $2017 ; 16: 1057$.

39. Lundberg U. Stress hormones in health and illness: the roles of work and gender. Psychoneuroendocrinology. 2005;30(10):1017-21.

40. Tang X, Tang S, Ren Z, Wong DFK. Psychosocial risk factors associated with depressive symptoms among adolescents in secondary schools in mainland china: A systematic review and meta-analysis. J Affect Disord. 2020;263:155-65.

\section{Figures}

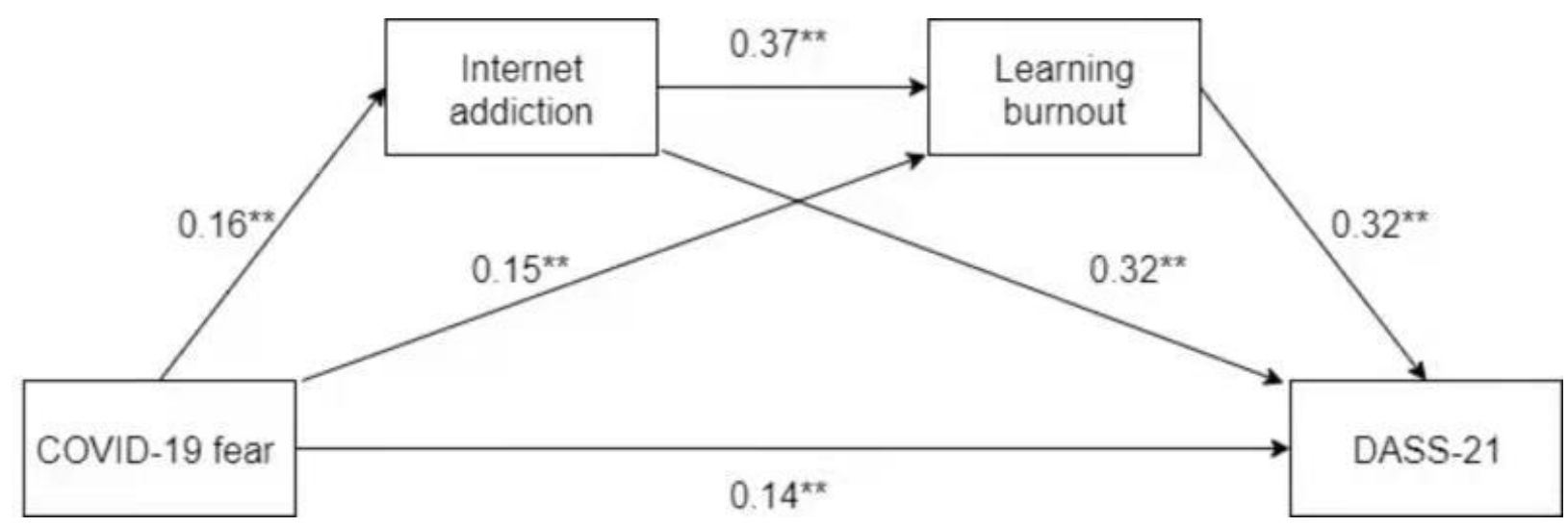

\section{Figure 1}

Associations between COVID-19 fear and psychological health. Serial mediation analysis with Internet addiction and learning burnout as serial mediators. 